\title{
Enhanced Urban Sprawl Monitoring over the Entire District of Rome through Joint Analysis of ALOS AVNIR-2 and SENTINEL-2A Data
}

\author{
Emanuele Loret ${ }^{1}$, Luca Martino ${ }^{2}$, Maurizio Fea ${ }^{3}$, Francesco Sarti ${ }^{4}$ \\ ${ }^{1}$ Department of Civil Engineering and Computer Science (DISP), University of Rome "Tor Vergata", Rome, Italy \\ ${ }^{2}$ Directorate of Earth Observation Programmes, EOP-G Department, European Space Agency (ESA), Frascati, Italy \\ ${ }^{3}$ Council of Presidency, Italian Geophysical Association (AGI), Rome, Italy \\ ${ }^{4}$ Earth Observation Science Strategy, Coordination and Planning Office, Directorate of Earth Observation, European Space \\ Agency (ESA), Frascati, Italy \\ Email: loret@disp.uniroma2.it, luca.martino@esa.int, maufea@gmail.com, francesco.sarti@esa.int
}

How to cite this paper: Loret, E., Martino, L., Fea, M. and Sarti, F. (2017) Enhanced Urban Sprawl Monitoring over the Entire District of Rome through Joint Analysis of ALOS AVNIR-2 and SENTINEL-2A Data. Advances in Remote Sensing, 6, 76-87. https://doi.org/10.4236/ars.2017.61006

Received: February 3, 2017

Accepted: March 5, 2017

Published: March 8, 2017

Copyright (C) 2017 by authors and Scientific Research Publishing Inc. This work is licensed under the Creative Commons Attribution International License (CC BY 4.0).

http://creativecommons.org/licenses/by/4.0/

\begin{abstract}
Based on the continuation of our past study, the present analysis is conducted to examine recent effects of the urbanization process occurring over the entire district of Rome. Overlays of ALOS AVNIR-2 and SENTINEL-2A satellite images, collected over a 6 years period, were validated via Geographic Information System (GIS) techniques, in a particular procedure applied to urban land and agricultural transformations. The use of Copernicus SENTINEL-2A imagery has improved the previous results on urban processes, by reducing the uncertainty of the discrimination of land cover classes and facilitating the photo-interpretation. Statistical analysis was performed via the Urban Area Profile index in order to quantify the sprawl phenomenon, by defining several landscape metrics. This work, to be enriched in the future by means of complementary information available from Copernicus radar sensors, like the one onboard Sentinel-1, completes the series of observations on land use published by the Italian National Institute for Environmental Protection and Research, which stopped back in 2008.
\end{abstract}

\section{Keywords}

UAP Index, Copernicus, ALOS AVNIR-2, SENTINEL-2A, GIS, Urban Sprawl

\section{Introduction}

Nowadays continuous remote sensing monitoring of urban areas is required all over the world in order to a) keep track of the loss of natural zones due to urban development and b) support urban planning activities [1]. Urban areas are par- 
ticularly vulnerable, not only because of the concentration of population but also due to the interplay that exists between people, infrastructures and natural or man-made risks [2]. In the last decades remarkable urban sprawl took place in Rome [3], especially along the consular roads, which are still the principal infrastructures available for transportation, causing significant environmental impacts, whereby natural surfaces were replaced by buildings, with the consequence of disappearance of vegetated areas, increased soil sealing and atmospheric pollution [4]. The road network constitutes in fact the key geographic object spatially structuring the urban growth of Rome and represents a good target for any aerial and multi-temporal satellite view. The overall objective of this paper, based on the continuation of our past study [5] [6] and [7], was to demonstrate the utility of the application of innovative GIS urban area profile indicators, derived from multi-temporal and multi-source optical remote sensing imagery, for assessing both the spatiotemporal dynamics and the extent of urban sprawl phenomenon over the entire municipality of Rome. Accurate mapping of land cover from high resolution Advanced Visible and Near Infrared Radiometer type 2 (AVNIR-2) sensor from Advanced Land Observing Satellite (ALOS) and SENTINEL-2A optical datasets provided essential input to urban expansion analysis. The European Earth Observation satellite SENTINEL-2A, successfully launched on June 2015, thanks to the innovative wide swath highresolution Multispectral Imager (MSI), permitted for an unprecedented view and enhanced classification of the urban landscape [8].

\section{Literature Review}

Over the last three decades, we have learned an awful lot about how to do remote sensing on an experimental, a scientific and a qualitative basis. Optical Earth Observation technology has enabled new applications like urban planning, monitoring of vehicles, mapping of building heights in urban environments or looking at detailed changes in the environment that might affect the wildlife. Modern optical sensors can capture both qualitative imagery and quantitative information, by using a range of different wavebands of light. Once processed imagery is often in a familiar "photographic" form, showing the Earth from the unique and powerful perspective of space. But it can also contain additional information useful to understand more about the natural and man-made processes occurring on urban zones [9]. Although several techniques to extract the land uses from optical remotely sensed data have been evolving, mapping urban landscape with enough accuracy is still not completely achieved [10]. This paper aims to quantify the sprawl phenomenon over the fast growing urban area of the district of Rome by using ALOS AVNIR-2 and SENTINEL-2 data. An updated state of the art on urban cover mapping using ALOS AVNIR-2 images is available at the JAXA ALOS Principal Investigators web page, Land Use \& Land Cover section [11]. For the purpose of this study, the usage of ALOS AVNIR-2 imagery was favorable due to the clear delineation of urban land use boundaries at a $10 \mathrm{~m}$ spatial resolution. Unfortunately the ALOS Satellite, after five years of service, lost power and ceased communication with Earth, in 2011 [12]. It is known that 
the ability to provide long term observations of the same area in the same way is one of the critical requirements for doing remote sensing for land use change. In this context the Sentinel program came to our aid. Within the frame of the Copernicus framework [13], ESA is in fact developing a series of missions that are complementary to one another, in order to provide continuity and long term, gap free data record [14]. The recent launch of the SENTINEL-2A satellite made available data with a minimum spatial resolution of $10 \mathrm{~m}, 13$ spectral bands, wide acquisition coverage and short time revisits, which opened a large scale of new applications [15]. SENTINEL-2A data ensured basic observing continuity with ALOS mission over the area of study and improved the previous results on urban processes, by reducing the uncertainty of the discrimination of land cover classes and facilitating the photo-interpretation. The red, green, and blue spectral bands taken at 10 meters spatial resolution, allowed discrimination of individual features of large buildings, roads and small fields, namely to spot an awful lot of new details that are crucial in terms of land use change applications. The literature on urban sprawl is bigger than the scope of this paragraph but in depth state of the art was recently prepared by Prof. Reid H Ewing [16]. While several environmental indicators have been developed in the recent years, their derivation from remote sensing and GIS data can be considered a relatively new field of research. To assess the impact of the urban sprawl over the entire district of Rome, the urban area profile indicator (UAP index) was adopted and, accordingly, a forecasting model was used to identify the areas with the higher risk of change within the reference period [6]. A number of different image processing, analysis and classification methods are available in order to generate land cover maps from high resolution optical remote sensing data; the choice of one method rather than another depends on the physical characteristics of the study area, the temporal distribution of the available imagery and the nature of the classification problem itself [17]. For the present work we refer to our previous publications [6] and [7].

\section{Study Area}

Rome is the largest city and commune in Italy and it is also one of the fast growing urban agglomeration in the world. The area of study was initially restricted to the GRA ${ }^{1}$, which encloses a surface of approximately $345 \mathrm{~km}^{2}$. Outcomes from our past study highlight how SPOT-4 and SPOT-5 available imagery, had been useful for computing precise urban density variations over an area included within the GRA, for the time frame 2002-2011. Results, spotting a noticeable urban expansion trend toward the north-eastern quarter of the city, were further validated against one very high resolution Kompsat-2 image, acquired in 2013 [6]. The present study extends the analysis beyond the GRA to the entire municipality (district) of Rome. The Eternal city is in fact characterized by a large municipal territory (see Figure 1), amounting to about $1290 \mathrm{~km}^{2}$ (district of Rome), out of which $877 \mathrm{Km}^{2}$ are no longer buildable, defining the socalled ${ }^{1}$ GRA stands for Grande Raccordo Anulare (literally, “Great Ring Road”), i.e. a toll-free ring-shaped orbital motorway- $68.2 \mathrm{~km}$ in circumference-that encircles Rome. 
"open area" of Rome, actually the largest in Europe [18].

\section{Materials}

The complete dataset used for the evaluation of urban growth over the entire district of Rome, includes ALOS AVNIR-2 and SENTINEL-2A satellite remote sensing images plus one 1:10,000 Regional Technical Map (CTR) map, one panchromatic and color ortho-photo and one QuickBird-2 for image to image co-registration (see the list of available sensors in Table 1). Data were gathered from ESA Sentinels Scientific Data Hub [19] and other available sources. Each mission used its own unique suite of instruments to explore the territory and, from their combined results it has been possible to find a wealth of interesting properties of the surface of interest.

Values in reflectance indices between land use species may vary at key times of the year and this can impact urban sprawl analysis from a remote sensing perspective. Timing of image acquisition has therefore important implications on the spectral response of land and agricultural ecosystems. According to literature [4] best time frame for Central/South Italy image acquisitions goes from early May to end of August. For the purpose of this study, one ALOS AVNIR-2 and two SENTINEL-2A images, acquired respectively on 21/05/2010, 30/08/2015 and 28/08/2016 were in fact used, taking advantage of 4 multispectral bands

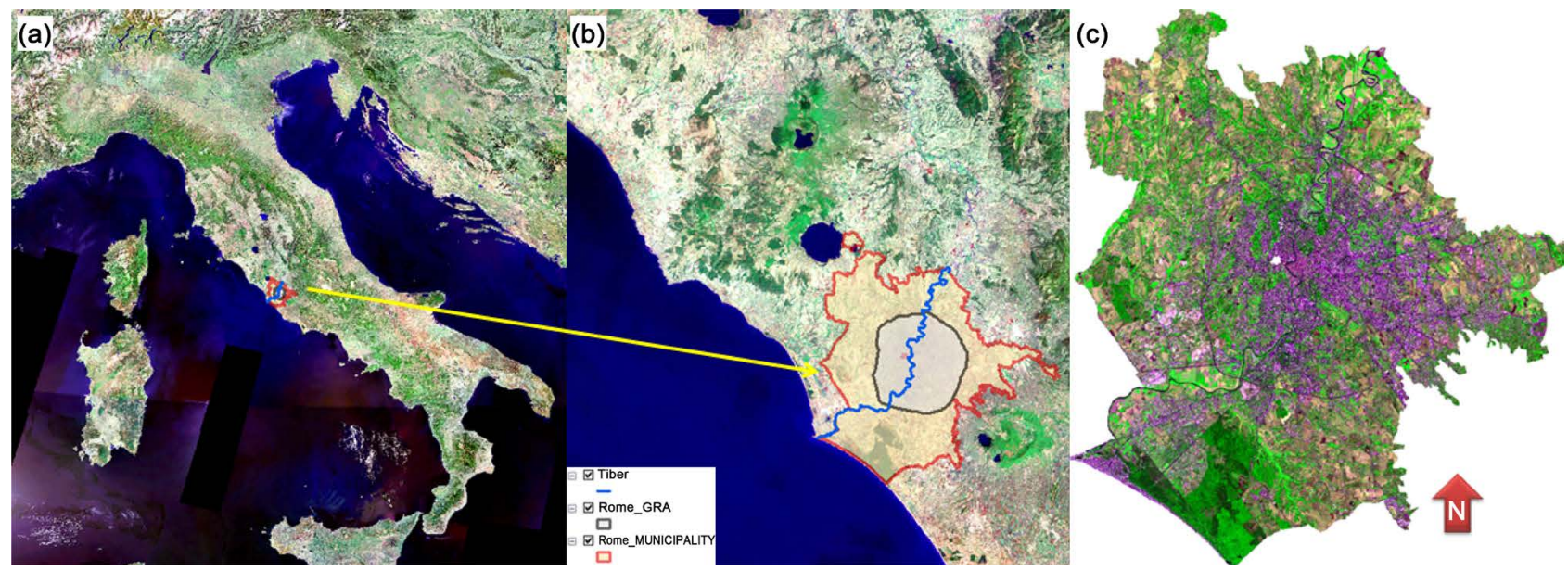

Figure 1. The large Roman urban area (a) geographical location as seen from the $150 \mathrm{~m}$ resolution natural colour Global Landsat Mosaic (courtesy of ESRI Italia); (b) vector layer boundaries of the municipality (red) and the internal GRA (black); (c) enhanced view of the district of Rome as derived from the ALOS AVNIR-2 2010 (RGB 3,4,2).

Table 1. Mission, sensors and products type.

\begin{tabular}{ccccc}
\hline Mission & Sensor & Product type & Resolution & Year \\
\hline CTR & & MAP & $1: 10,000$ & 1990 \\
Aerial imagery & & Ortophoto PAN & $50 \mathrm{~cm}$ & 2000 \\
QuickBird-2 & BGIS & MS + PAN & $60 \mathrm{~cm}$ & 2002 \\
ALOS & AVNIR2 & MS & $10 \mathrm{~m}$ & 2010 \\
SENTINEL-2A & MSI & MS & $10 \mathrm{~m}$ & $2015 / 2016$ \\
\hline
\end{tabular}


Table 2. Software packages.

\begin{tabular}{cccc}
\hline Software & Version & Developed by & Description \\
\hline ERDAS Imagine & 11.0 .2 & INTERGRAPH & Geospatial image processing \\
Sentinel 2 Toolbox & 5.0 & ESA & Image analysis \\
SNAP & 5.0 & GNU GPL v3 & Image display and navigation \\
ENVI & 5.0 & EXELISVIS & Geospatial image processing \\
Arc INFO & 9.3 & ESRI & GIS-Terrain Model Mapping \\
\hline
\end{tabular}

(blue, green, red and near infrared) having similar spectral resolution $(10 \mathrm{~m})$ and range (see Figure 2). As outlined in Table 2, a wide range of proprietary and open source software programs were used in this research for accomplishing different tasks. For remote sensing image analysis, processing, mosaicking and manipulation the following tools were employed: (a) ERDAS Imagine ${ }^{2}$, (b) ENVI service pack ${ }^{3}$, (c) Sentinel 2 Toolbox and, (d) the Sentinel's Application Platform (SNAP) $)^{4}$. For GIS statistical analysis, digitalization, measurement tasks, identification and rendering of surface features, as well as soil high resolution mapping and detailed site characterization for potential urbanized areas, the Arc GIS $9.3^{5}$ software was used.

\subsection{Methodology}

The methodology has involved a) image processing, b) classification, c) measurement and d) interpretation of the results. Available imagery enabled a direct comparison of different areas of interest across the surface of the city, allowing visual interpretation and validation for urban growth. ALOS AVNIR-2 and SENTINEL-2A images, already radio-metrically corrected, have been geo-referenced and co-registered against a very high resolution $(0.6 \mathrm{~m})$ QuickBird-2 base image (acquired in 2002) through a number of 96 ground control points (RMS 0.32) [20]. Images have been then resampled through the nearest-neighbor interpolation technique. For the purpose of this study the UTM-ED1950/33N coordinate system was adopted. Raster layers have been then vectorized and ingested into a multi-relational GIS database for scientific management and orientated information. Spatial subsets for each image were created against the area of interest. A maximum likelihood supervised classification was run (Figure 2), in order to categorize image pixels, into initially seventeen classes, thereafter merged into four main groups displayed with color codes.

Each subset contains information on the features identified over the selected area of interest (vegetated, urbanized, and so on). Following identification of the main spectral classes, ad-hoc corrections were applied for improving difficult target discrimination when same radiance values occurred, as in the case of tiled roofs presenting rural field like spectral response. Survey of the urbanized classes

${ }^{2}$ ERDAS Imagine, Intergraph, available at http://www.intergraph.com ${ }^{3}$ ENVI 5 Service Pack 3, Exelis, available at http://www.exelisvis.com ${ }^{4}$ ESA Sentinel Application Platform (SNAP), available at http://step.esa.int/main/toolboxes/snap/ ${ }^{5}$ Arc GIS 9.3, ESRI, available at http://www.esri.com/software/arcgis 
has been executed to understand the evolution of surface expansion and the densely populated areas (Table 3 and Figure 3). Assessment of the building density has been performed as well. Kernel function was duly applied to "centroids" of each building while a $10 \mathrm{~m} \times 10 \mathrm{~m}$ "GRID" file (raster format) has been obtained for the estimation of the statistical values. The GRID file has been subsequently reclassified into 5 classes (GRID codes), corresponding to already acknowledged field values with output data ranging from "very low" to "very high" values. Following that, the GRID file has been converted back into vector format preserving the values of the 5 classes in the attribute table; then it has been cut at the area of interest. Results have been analyzed using the urban area

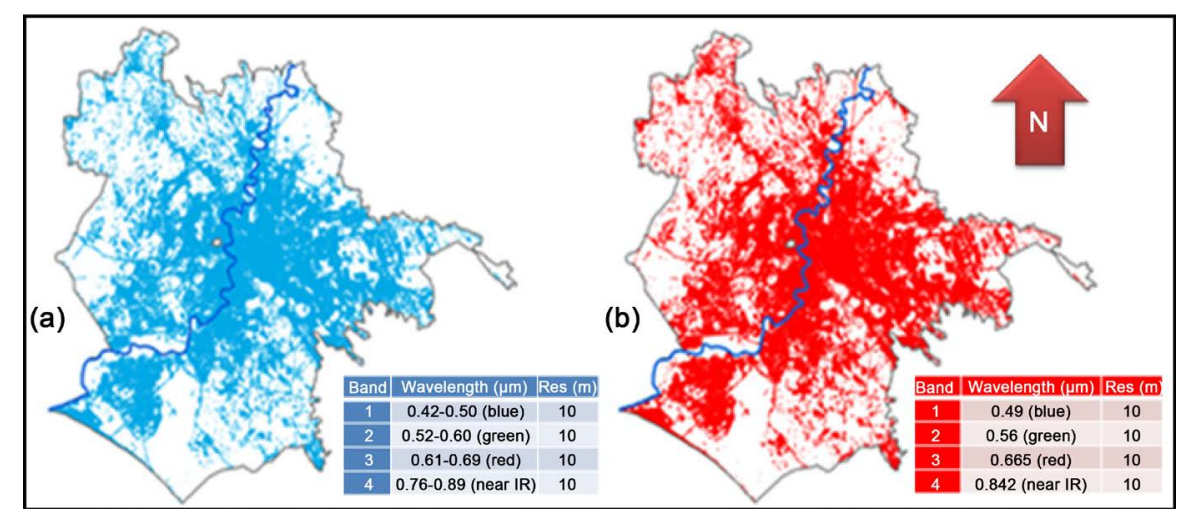

Figure 2. 4 Spectral bands with similar resolution and range from available imagery plus GIS geostatistical maps showing urban coverage spread over the municipality of Rome as derived from supervised classification: (a) ALOS AVNIR-2(2010); (b) SENTINEL-2A (2016).

Table 3. Variation of the surface extension of the city of Rome from 1900 until 2016. Urban growth analysis of the district of Rome through optical satellite images starts with supervised classification run over one Landsat TM image, acquired in 1996 [5]. Historical maps were geo-referenced, vectorized and integrated into a GIS system for analysis of the urban system expansion since the early twentieth century [7].

\begin{tabular}{ccccccccc}
\hline & 1900 & 1925 & 1930 & 1960 & 1986 & 2010 & 2015 & 2016 \\
\hline Acquisition & map & map & map & map & Landsat-5 & ALOS & SENTINEL-2A SENTINEL-2A \\
Surface $\left(\mathrm{Km}^{2}\right)$ & 18.8 & 24.4 & 29.7 & 94.9 & 215.1 & 324.4 & 354.54 & 354.75 \\
Municipality (\%) & 1.46 & 1.90 & 2.31 & 7.37 & 16.71 & 25.20 & 27.54 & 27.56 \\
\hline
\end{tabular}

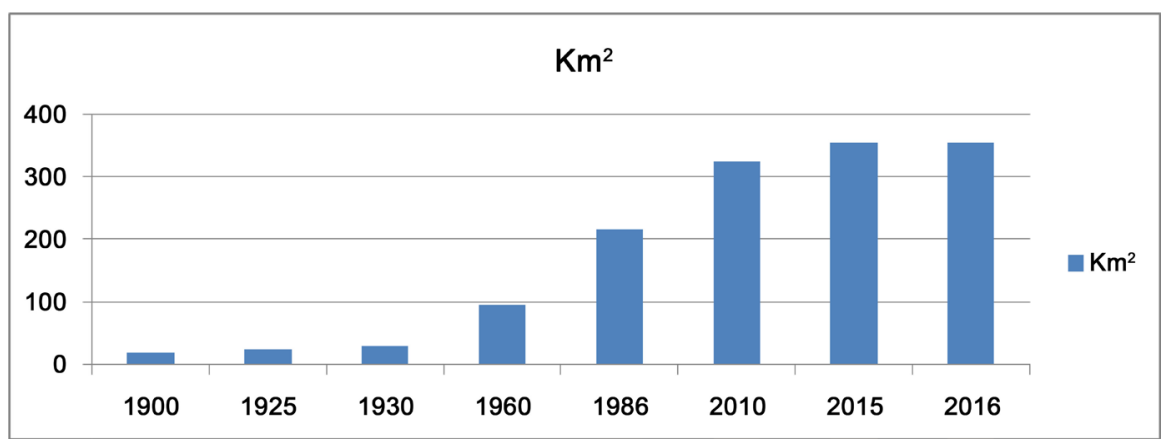

Figure 3. Overall urban growth of the municipality of Rome from 1900 until 2016. 
profile (UAP) index [7].

\subsection{The UAP Index for Urban Sprawl Measurement}

UAP index allows the measurement of the spatial profile of each land use class over a fixed area of interest, and it is based on a geo-statistical approach [6].

The Urban Area Profile Index formula is:

$$
U A P_{x i}=\frac{S_{x} \cdot\left(C_{i} / C_{t}\right)}{S_{t}}
$$

and the overall density value for a specific land use $\mathrm{x}$ :

$$
U A P_{i}=\sum_{x} \frac{S_{x} \cdot\left(C_{i} / C_{t}\right)}{S_{t}}
$$

where

$U A P_{x i}$ is the urban area profile index for the density class $i$ and the land use $x$;

$S_{x}$ is the total area for the specific land use $x$;

$C_{i}$ is the number of cells in the density class $i$;

$C_{t}$ is the total area cells and St is the total municipal area.

\subsection{Validation of Results}

The UAP index (1) has been defined in order to produce a quantitative descriptive summary of the spatial arrangement of the different land uses, which allows to easily understand the environmental or multi-temporal framework of the territory [7]. A logical model has been adopted to evaluate the UAP index. It is based on the measurement of spatial relationships among the density distribution (2) of each land use and on the comparison of each distribution with the total amount of each specific land use area. To simplify the system, the study area has been divided in two land use classes: urban 2010 and urban 2016 [20]. The UAP index has been applied to analyze the specificity of a single year and to compare each year's profile with the entire urban expansion. From the analysis of density values of both ALOS and SENTINEL-2A images, it has been possible to observe a continuous urbanization trend of the free surfaces spread over the district of Rome (Table 4 and Figure 4). In particular in 2010 the urban area covers about $25 \%$ of the territory of the municipality while in 2016 roughly $27 \%$ of total area of interest: this means that the urban area has increased of about 30 $\mathrm{Km}^{2}$ in only six years, going from $324.4 \mathrm{Km}^{2}$ in $2010,354.54 \mathrm{Km}^{2}$ in 2015 up to $354.75 \mathrm{Km}^{2}$ in 2016.

\section{Discussion}

Aim of this study has been the measurement of the growth trend of a big town like Rome in terms of land consumption. GIS analysis has offered an enhanced understanding of the present and future trends that a city such as Rome will face [17]. As a matter of fact, the analysis of urban land use obtained by deriving the UAP index from satellite image data acquired by ALOS AVNIR-2 and SENTINEL-2A 
Table 4. Density values comparison in $\mathrm{Km}^{2}$, between ALOS AVNIR-2 and SENTINELl2A satellite data.

\begin{tabular}{cccccc}
\hline Sensor & \multicolumn{5}{c}{ Density $\left(\mathrm{Km}^{2}\right)$} \\
\hline & very low & low & medium & high & very high \\
\hline ALOS AVNIR-2 [2010] & 794.4 & 126.07 & 108.9 & 112.3 & 144.95 \\
SENTINEL-2A [2016] & 734.7 & 146.6 & 127 & 126 & 136.7 \\
\hline
\end{tabular}

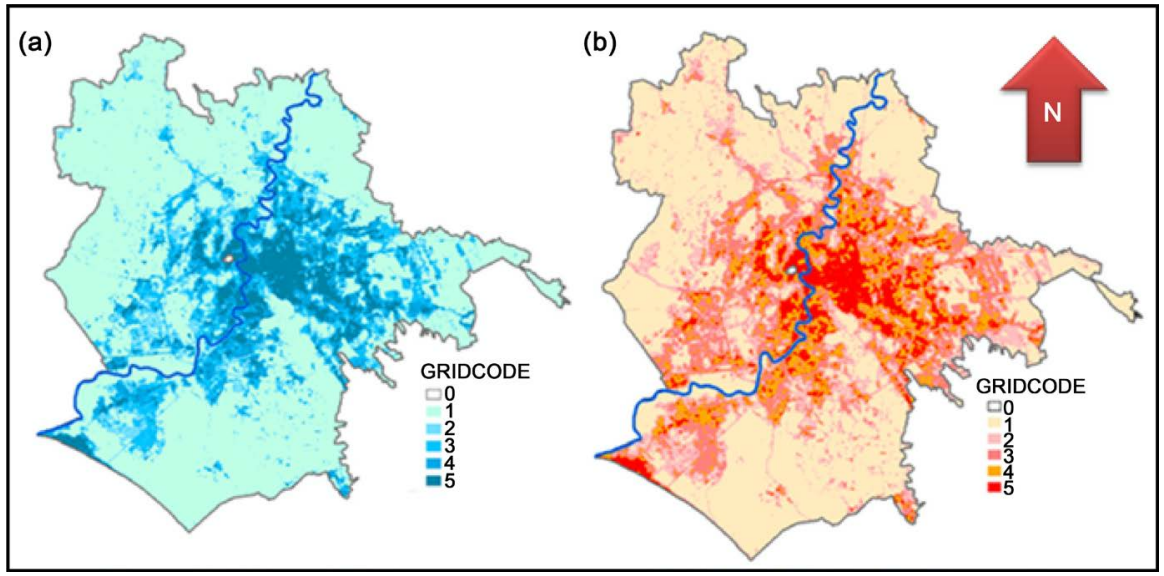

Figure 4. GIS maps of urban density classes (GRID codes) as derived from ALOS AVNIR-2 (a) and SENTINEL-2A (b) satellite data.

sensors, respectively in 2010, 2015 and 2016, has permitted the direct comparison both of land surfaces and of the index of percentage of consumed land with respect to the entire municipal surface: results have shown a clear growth of the anthropized surface (Table 5). In particular, urban areas derived from the aforementioned classification procedure have been processed in density classes and analyzed through the UAP Index. By comparing the ALOS AVNIR-2 and SENTINEL-2A UAP Indexes (Table 5 and Figure 5), it is possible to observe lower density values in 2016 than in 2010: this may be considered as an indication of the constant increase of the urban sprawl phenomenon, which seems to suggest a form of compacting and welding of the urban territory within the 6 years' time difference between acquisitions. This consideration is confirmed by the application of the dispersion coefficient or Variability Coefficient (VC) to the UAP index density data series where the decrease of 2016 value with respect to the 2010 one can be spotted as follows:

$$
\begin{aligned}
& V C_{\text {ALOS AVNIR-2 }}=\frac{S}{\bar{X}}=3.35 \\
& V C_{\text {SENTINEL-2A }}=\frac{S}{\bar{X}}=1.82
\end{aligned}
$$

where $S$ is the Standard Deviation and $X$ is the Mean.

Outcomes of the present analysis is well in agreement with values reported by the Italian National Institute for Environmental Protection and Research (ISPRA) where processing of cartographic data related to both the ISTAT administrative boundaries and the Imperviousness-Copernicus Land Monitoring 
Table 5. UAP Index density values comparison between ALOS AVNIR-2 (2010) and Sentinel-2A (2016) satellite data. To be noted that the very dense surfaces are also slightly decreased when compared to the classes "low", "medium" and "high".

\begin{tabular}{ccc}
\hline Density & \multicolumn{2}{c}{ UAP Index } \\
\hline & ALOS AVNIR-2 & SENTINEL-2A \\
\hline very low & 0.24 & 0.11 \\
low & 0.02 & 0.06 \\
medium & 0.01 & 0.04 \\
high & 0.01 & 0.02 \\
very high & 0.01 & 0.01 \\
\hline
\end{tabular}

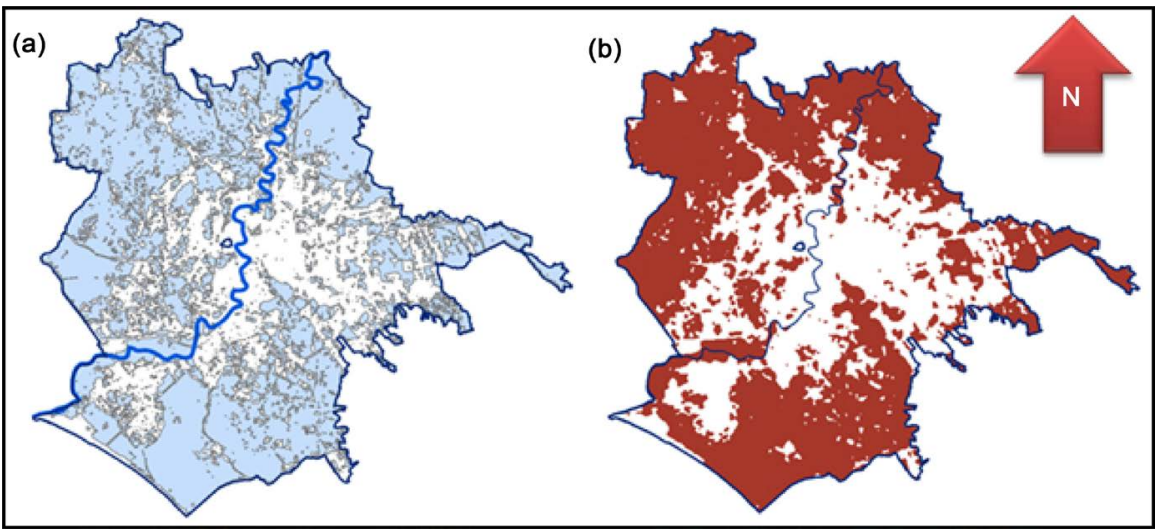

Figure 5. GIS overall synthesis map showing UAP "very low" index values comparison and didtribution as retrived by a) ALOS 2010 and b) SENTINEL-2A 2016.

Table 6. Surface extension comparison between ISPRA data and our satellite analysis.

\begin{tabular}{cccccc}
\hline Rome municipality & \multicolumn{2}{c}{ ISPRA analysis } & \multicolumn{3}{c}{ Satellite analysis } \\
\hline Year & 2005 & 2008 & 2010 & 2015 & 2016 \\
$\mathrm{Km}^{2}$ & 322.75 & 334.96 & 324.4 & 354.54 & 354.75 \\
$\%$ & 25.1 & 26.1 & 25.2 & 27.54 & 27.56 \\
\hline
\end{tabular}

Services, was done taking advantage of sequence of satellite acquisitions close in time. Taking in fact into account only the values of the ISPRA temporal series nearest to those of the mentioned satellite missions, the results are quite similar. From ISPRA the consumed land values are $322.75 \mathrm{Km}^{2}$ in 2005 and $334.96 \mathrm{Km}^{2}$ in 2008 [21], compared with $324.4 \mathrm{Km}^{2}$ in 2010 and $354.7 \mathrm{Km}^{2}$ in 2016 from satellite data. In terms of percentage, values from ISPRA are $25.1 \%$ in 2005 and $26.1 \%$ in 2008 [22], whilst satellite data indicate $25.2 \%$ in 2010 and $27.5 \%$ in 2016 (Table 6).

\section{Conclusion}

Land use and land cover mapping have been core applications of Earth Observation from its inception to today, and so data spanning over several decades is now available. The NASA Landsat missions along with France's SPOT missions have monitored land use for more than a generation, and the Copernicus Senti- 
nel-2A has now taken up the mantle. However, one of the major problems encountered with urban sprawl measurement in the last decades, has been dealing with the lack of classification accuracy due to differences in spatial and spectral resolution from available remote sensing imagery. For urban growth monitoring of heterogeneous areas, such as those including urban settlements spread over the district of Rome, satellites such as ALOS and SENTINEL-2A, have proven to be necessary. The analysis of the results, as shown in Figure 5, demonstrate that the urbanization trend is positive within the study area and it is filling up (compaction of the dispersal areas) the remaining gaps left by the sprawl phenomena previously occurred. Much of the impetus for this inexorable phenomenon has been favored by a lack of coordination of land use policies adopted by the various municipalities. It's known that measuring land use change is important on local, regional, national, and international scales, and underpins many of the international efforts to monitor and respond to man-made impacts on the environment [24]. The result of this investigation is therefore also meant to offer to Administrators and Decision Makers an additional tool for their technical offices for an improved monitoring and consequent planning of the urban expansion. Based on comparisons with our previous work, we found that ALOS AVNIR-2 [23] and Sentinel-2A data provided more accurate land cover/land use classification of the district of Rome. Sentinel-2A mission is routinely providing global high-resolution optical imagery and offering enhanced continuity of SPOT and Landsat-type data (Lefebvre, 2016). However since the ALOS satellite is no longer operational, it will be necessary for future epochs to employ data from different sensors with different specifications. In particular future extension of this research will be focused on the in depth analysis of the master plans defined for Rome over the last 30 years [25]. Once operational, the combination of the SENTINEL-2 constellation imagery, its wide swath of $290 \mathrm{~km}$ and the satellite's frequent revisit times will provide unprecedented views of the large roman urban system expansion. Taking advantage of the recently launched radar missions Sentinel-1A and $B$, as well as of the available huge radar archive of the previous ESA missions such as ERS-1,2 and ENVISAT, Synthetic Aperture Radar (SAR) image data will be concurrently processed and integrated into the GIS multi-relational database thus allowing an easier discrimination of the urban landscapes, especially in a dense and heterogeneous city such as Rome. Due to SAR pulse illumination along a slant range, backscatter radar pulse values from an urban environment are highly dependent on the radar frequency, polarization, viewing geometry and shadow effects. SAR imagery allows detecting urban features in a complementary way with respect to the optical one and the limitations of SAR and optical sensors for urban areas discrimination will be adequately compensated by appropriately combining the information extracted from each sensor [26].

\section{Acknowledgements}

The support of ESA/ESRIN in image availability and technical tools is kindly 
acknowledged.

\section{References}

[1] Donnay, J.P., Barnsley, M.J. and Longley, P.A. (2001) Remote Sensing and Urban Analysis. Taylor \& Francis, London, 3-18.

[2] EEA-European Environment Agency (2006) Urban Sprawl in Europe-The Ignored Challenge. EEA Report No. 10.

[3] Comune di Roma (2008) Le metropoli della città, Ufficio di Statistica e Censimento. Sistema Statistico Nazionale, Roma.

https://www.comune.roma.it/ www.demo.istat.it

[4] Watts, M. (2011) Climate Action in Mega-Cities: C40 Cities. Web Report, ARUP, New York

[5] Loret, E. and Cadoni., F. (1998) Elaborazione di immagini tematiche derivate da integrazione di dati telerilevati nel monitoraggio dell'Area Metropolitana romana. Associazioni per le Informazioni Territoriali ed Ambientali (ASITA), Bolzano.

[6] Loret, E., Martino, L., Fea, M. and Sarti, F. (2015) Combined Remote Sensing and GIS Techniques for Studying the Large Roman Urban System Expansion during the Last Twenty Years. Advances in Remote Sensing, 4, 48-62. https://doi.org/10.4236/ars.2015.41005

[7] Martino, L. and Loret, E. (2015) Integration of Historical Maps and Muti-Temporal Optical Remote Sensing Data into a GIS System for Studying of the Large Roman Urban System Expansion Since the Early Twentieth Century. Mapping Urban Areas from Space-MUAS. European Space Agency-ESRIN, Frascati, Rome, 28.

[8] Sentinel-2 MSI-User Guides (2016). https://earth.esa.int/web/sentinel/user-guides/sentinel-2-msi/

[9] Elachi, C. (2006) Introduction to the Physics and Techniques of Remote Sensing. Wiley, New Jersey. https://doi.org/10.1002/0471783390

[10] Scott, D.W. (1992) Multivariate Density Estimation: Theory, Practice and Visualization. John Wiley, New York. https://doi.org/10.1002/9780470316849

[11] JAXA (2012) ALOS Principal Investigators List (3rd RA) — Land Use \& Land Cover. http://www.eorc.jaxa.jp/ALOS/en/ra/ra3_mem/ra3_mem_land.htm

[12] JAXA (s.d.) ALOS. http://global.jaxa.jp/projects/sat/alos/topics.html

[13] EC Copernicus Europe's Eyes on Earth (2017) http://www.copernicus.eu/

[14] ESA (2017) Sentinel Missions. https://sentinel.esa.int/web/sentinel/missions

[15] Lefebvre, A. (2016) Degree, Monitoring Urban Areas with Sentinel-2A Data: Application to the Update of the Copernicus High Resolution Layer Imperviousness. Remote Sensing, 8, 606. https://doi.org/10.3390/rs8070606

[16] Ewing, R.H. (2008) Characteristics, Causes, and Effects of Sprawl: A Literature Review. In: Marzluff, J.M., et al., Eds., Urban Ecology, Springer, New York, 519-535. https://doi.org/10.1007/978-0-387-73412-5_34

[17] Bhatta, B. (2010) Analysis of Urban Growth and Sprawl from Remote Sensing Data. Springer, Heidelberg, 172. https://doi.org/10.1007/978-3-642-05299-6

[18] Berdini, P. (2008) La città in vendita. Donzelli, Rome.

[19] ESA (s.d.) Sentinel-2A Mission. https://sentinel.esa.int/web/sentinel/missions/sentinel-2 
[20] Loret, E. (2012) Spatial Analysis of the Increasing Urbanization Trend in the Frascati Wine Designation of Origin (DOC) Area: A Geostatistical Approach. Journal of Geography and Regional Planning, 5, 346-352.

[21] Casacchia, O. and Crisci, M. (2013) La popolazione dell'area metropolitana di Roma. Evoluzionedemografica e previsioni al 2024, IRPPS Working Papers.

[22] Munafo, M. (2014) Il consumo di Suolo. Suolo e territorio-ISPRA, Italy, 66-71.

[23] Yamamoto, Y. (2012) ALOS/AVNIR2 Band Reflectance Characteristics of Buildings in Land Use Zones-A Case Study of Nagoya City. ASPRS, US.

[24] Arellano, B. (2010) The Urban Sprawl in Megacities, It Is an Unsustainable Model? Arquitectura, 4, 115-147.

[25] Morassut, R. (2005) Roma capitale nel XXI secolo: La città metropolitana policentrica. Palombi, Rome, 207.

[26] Martino, L. (2009) Remote Sensing and GIS Techniques for Natural Disaster Monitoring. In: Olla, P., Ed., Space Technologies for the Benefit of Human Society and Earth, Springer, Livonia, 331-382. https://doi.org/10.1007/978-1-4020-9573-3_14

Submit or recommend next manuscript to SCIRP and we will provide best service for you:

Accepting pre-submission inquiries through Email, Facebook, LinkedIn, Twitter, etc. A wide selection of journals (inclusive of 9 subjects, more than 200 journals)

Providing 24-hour high-quality service

User-friendly online submission system

Fair and swift peer-review system

Efficient typesetting and proofreading procedure

Display of the result of downloads and visits, as well as the number of cited articles

Maximum dissemination of your research work

Submit your manuscript at: http://papersubmission.scirp.org/

Or contact ars@scirp.org 